\title{
Caracterización y monitoreo de paisaje semiárida en la Región del Maule mediante datos satelitales
}

\author{
Carlos M. Frau ${ }^{1}$, João R. Santos ${ }^{2}$, Francisco D. Maldonado ${ }^{3}$, John G. Valenzuela ${ }^{1}$, \\ Marcio M. Valeriano ${ }^{2}$, Yony 0. Rojas $^{1} \&$ Yohana M. Hernández ${ }^{1}$
}

\begin{abstract}
RESU MEN
El objetivo del trabajo es aplicar la técnica Rotación Radiométrica Controlada por Eje de No-cambio (RCEN) en imágenes Landsat TM de los años 2004 y 2008, para la región semi-árida del Maule, Chile. Esta aplicación tiene el fin de obtener la distribución espacial de los cambios del paisaje forestal. El procedimiento de RCEN permite el uso de imágenes sin corrección atmosférica, combinado a un método empírico para seccionar y legendar la imagen de cambio basado en las observaciones de campo. El índice Kappa para la imagen temática del cambio fue 0.74 indicando que, durante el período considerado por la detección, los porcentajes de recuperación y la degradación la vegetación fueron 17 y $5 \%$ respectivamente. Datos altimétricos de SRTM (Shuttle Radar Topography Mission) fueron utilizados para obtener la pendiente y la distribución de las clases de cambios en relación a esta. La mayor parte de la superficie de la clase nocambio está localizada en altas y bajas declividades. En la categoría de recuperación de la vegetación, la mayor proporción tiene lugar en el rango de declividad 10 a 50\%. Por otra parte, la pérdida de vegetación es uniformemente distribuida en todos los gradientes de declividad.
\end{abstract}

Palabras clave: semiárido, detección de cambios, percepción remota, rotación radiométrica

\section{Characterization and monitoring of semi-arid landscape in the Maule region from satellite data}

\begin{abstract}
The objective of this research is to apply the Radiometric Rotation Controlled by No-change Axis (RCNA) technique on Landsat TM images, 2004 and 2008, covering the coastal dry land of the Region of Maule, Chile, in order to obtain the spatial distribution of changes and degradation in the forest landscape. The RCNA procedure allows the use of images without atmospheric calibrations, whose empirical method for the label was based on field observations. The Kappa Index for the change thematic image was 0.74 , showing that the recovery and loss of vegetation were 17 and $5 \%$, respectively. SRTM (Shuttle Radar Topography Mission) data were used to derive slope angle, where the major proportion of no-change surface occurs in areas of high and low slope. In the category of recovery of vegetation, the major proportion takes place in the $10-50 \%$ slope class. $0 n$ the other hand, the loss vegetation is uniformly distributed through the whole gradient of the slope angle.
\end{abstract}

Keywords: semi-arid, change detection, remote sensing, radiometric rotation

1 Centro de Geomática. Universidad de Talca. Av. Lircay S/N., Talca, Chile. Fone: (56) 71-201702. E-mail: cmena@utalca.cl; jgajardo@utalca.cl; yormazabal@utalca.cl; ymorales@utalca.cl

2 Instituto Nacional de Pesquisas Espaciais - IN PE/MCT, Av. dos Astronautas, 1758, CEP 12227-010, São José dos Campos, SP. Fone: (55) 12-3945-6427. E-mail: \{jroberto,valerian\}@dsr.inpe.br

3 Fundação de Ciências, Aplicações e Tecnologias Espaciais (FUNCATE). Av. Dr. João Guilhermino, 429, 18 Andar, CEP 12210-131, São José dos Campos, SP. Fone: 55-12-3925-1391. E-mail: francisco.dario.maldonado@gmail.com 


\section{INTRODUCCIÓN}

La desertificación ha sido catalogada como uno de los problemas socioambientales más agudos de Chile. Los territorios áridos y semiáridos afectados por estos procesos superan el $60 \%$ del territorio nacional, concentrándose los mayores daños en los suelos, biodiversidad y productividad silvoagropecuaria en general. Como consecuencia, la población rural inserta en estos ambientes sufre directamente los resultados de este fenómeno, registrando altos índices de pobreza, falta de oportunidades y fuertes tasas de emigración (CONAF, 1997).

La Región del Maule en particular presenta una gran extensión de vegetación nativa, cerca de 795.230 hectáreas, las cuales han sido fuertemente reemplazadas por plantaciones forestales y nuevos cultivos agrícolas intensivos como los viñedos y olivos, provocando pérdida y fragmentación de gran parte del hábitat natural (Echeverría et al., 2007). En este contexto, los bosques templados de Chile han sido cosechados para abastecer el incremento en la demanda global por madera y productos del papel, por lo que una cantidad sustancial de bosque se ha perdido debido a la conversión de bosque nativo a praderas de pastoreo, incendios provocados por el hombre, cortas selectivas y sustitución por plantaciones comerciales (Lara et al., 2000). Así, una de las mayores contradicciones del sector forestal chileno es que mientras ha habido un crecimiento notable de las exportaciones forestales a partir de plantaciones de pino y eucalipto, principalmente distribuidas entre las regiones VII a IX, la población de esas regiones no ha visto mejorada su calidad de vida (Donoso \& Otero, 2005).

Por otra parte, la vitivinicultura de Chile ha alcanzado un gran desarrollo en las últimas décadas, en especial desde 1997 en adelante, sin embargo, a pesar de sus altas tasas de crecimiento, tanto en niveles de producción como exportación, no ha provocado un aporte real al desarrollo de las áreas rurales en que se produce, como sucede en la Región del Maule, la región más especializada del país en este rubro. Contrariamente a lo que se piensa, se han observado grandes diferencias en los niveles de desarrollo al interior de un mismo valle, y el desencadenamiento de la actividad vitivinícola, ha redundado en un bajo desarrollo de la población local (Romero et al., 2004).

En este contexto, para la identificación, estimación y monitoreo de la degradación de tierras y otras problemáticas afines, han surgido como una tecnología eficiente las técnicas de detección de cambios desarrolladas a partir de sensores remotos. La detección de cambios a partir de una secuencia multitemporal de imágenes de satélite es una de las aplicaciones más importantes en teledetección (Radke et al., 2005). Este proceso requiere generalmente una adecuada corrección radiométrica y geométrica de las imágenes (Nelson et al., 2005), de manera que los cambios detectados sólo sean atribuibles a verdaderas modificaciones del paisaje.

La detección de cambios es un proceso que observa las diferencias de un objeto o fenómeno en distintos momentos. Varias técnicas de detección de cambios han sido desarrolladas (Lillestrand, 1972; Singh, 1989; Coppin et al., 2004;
Desclee et al., 2006). En general las técnicas de detección de cambios, emplean desde simples operaciones entre bandas espectrales (Rogan et al., 2002), hasta complejos algoritmos de cálculo, para detectar de mejor forma los cambios de interés (Song et al., 2001; Hall \& Hay, 2003; Le Hégarat-Mascle \& Seltz, 2004; Nackaerts et al., 2005; Liua et al., 2008; Berberoglu \& Akin, 2009).

Maldonado et al. (2007) y Graça et al. (2008) desarrollaron y aplicaron la técnica de Rotación Controlada por Ejes de No-Cambio (RCEN) para tratamiento de imágenes multiespectrales y multisensores, de bandas correlativas. La técnica es usada comúnmente para estimar y evaluar cambios en la cobertura del suelo, inclusive los cambios resultantes de desastres naturales, eventos climáticos extremos, hasta resultados de la implementación de políticas públicas o económicas. La técnica permite el uso de imágenes de satélite sin complejas correcciones atmosféricas en similares bandas espectrales.

En consecuencia, el trabajo tiene como objetivo principal la aplicación de la técnica RCEN, sobre imágenes Landsat TM de los años 2004 y 2008, localizadas sobre la zona del secano interior de la Región de Maule, Chile, evaluando el desempeño metodológico y espacialización de los cambios en el paisaje forestal, en términos de degradación y recuperación de masa boscosa.

\section{MATERIAL Y METODOS}

El área de investigación comprende una superficie de $1.577 \mathrm{~km}^{2}$, localizada entre los paralelos $71^{\circ} 53^{\prime}$ y $72^{\circ} 16^{\prime}$ de latitud sur y $35^{\circ} 12^{\prime}$ y $35^{\circ} 40^{\prime}$ de longitud oeste, la cual abarca territorios de las comunas de Constitución, Curepto, Empedrado, Pencahue y San Javier en la Región del Maule, Chile. La zona posee un clima mediterráneo cálido con un período seco de cinco meses entre Noviembre y Marzo, ciclo que presenta las temperaturas máximas promedio de $19^{\circ} \mathrm{C}$ y extremas de $30^{\circ} \mathrm{C}$ en los valles y cuencas interiores, en invierno las temperaturas mínimas promedio alcanzan un promedio de $7{ }^{\circ} \mathrm{C}$. En cuanto a las precipitaciones, éstas se concentran durante el invierno, permitiendo veranos secos con pocas nubes y una alta luminosidad, generando un promedio anual de $734 \mathrm{~mm}$ (Santibáñez et al., 1979).

Los suelos se encuentran en una categoría de valoración baja, presentando variaciones de capacidades de uso iguales o inferiores a IV. Esto involucra zonas con un imperfecto equilibrio entre el desarrollo del perfil (profundidad, horizontes, materia orgánica, entre otros) y las condiciones fisiográficas del área (drenaje, pendiente y composición litológica), restringiendo su uso a actividades predominantemente de carácter forestal y en menor manera a usos ganaderos y silvestres (CIREN, 1997).

La zona posee una estructura y composición de vegetación nativa dominada principalmente por bosque secundario de Nothofagus sp (N. oblicua y N. glauca) y especies esclerófilas que incluyen Acacia caven, Quillaja saponaria y Maytenus boaria (Gajardo, 1994), las que se encuentran fuertemente alteradas por la acción de la actividad forestal, cuyo 
dinamismo ha llevado a las formaciones nativas a distribuirse en pequeños fragmentos aislados, rodeados por plantaciones de Pinus radiata (Echeverría et al., 2007). En este contexto, el paisaje actual se muestra como el resultado de antiguos procesos empleados en el cultivo de cereales durante el siglo pasado, en donde grandes extensiones de bosques naturales fueron eliminados para la implantación de cultivos de trigo (San Martín \& Donoso, 1997). Asimismo, en décadas recientes, la extracción selectiva de árboles nativos para su uso como combustible domiciliario (leña), ha causado la degradación extrema de este recurso forestal.

\section{Aplicación de la técnica RCEN}

El primer paso para la detección de cambios con imágenes es el corregistro. Esto permite la correspondencia espacial entre los elementos que aparecen en cada una de las fechas. Las imágenes empleadas en la investigación correspondieron a subescenas tomadas de datos Landsat TM con órbita de 233/ 085, sin calibraciones o correcciones atmosféricas anteriores. Las fechas de las imágenes empleadas fueron 18 de marzo de 2004 y 25 de enero de 2008. Este corregistro tuvo un error medio RMS (Residuo Medio Cuadrático) menor de 0.3 (un tercio de píxel), pudiendo las imágenes ser utilizadas por una técnica de detección de cambios.

El tratamiento aplicado a los datos en el presente trabajo pertenece a un nuevo grupo de análisis de datos espectrales, diferente del uso directo de los valores digitales de las imagens (Lima et al., 1998), abordado por técnicas incorporadas en los Sistemas de Información Geográfica, como índices espectrales de vegetación, clasificadores supervisados por verosimilitud (Nascimento et al., 2006), o por otras técnicas más complejas como modelos lineales de mezcla espectral (Accioly et al., 2002) y la relativamente reciente abordage por redes neuronales artificialess (Chagas et al., 2009). La modalidad de la técnica rotación radiométrica tratada en este trabajo, busca directamente los cambios de uso de las tierras, a través de los residuos de una regresión a una recta definida entre dos bandas de fechas diferentes.

La técnica empleada es la RCEN - Rotación Controlada por Eje de No Cambio (Maldonado et al., 2007). Esta técnica de detección (Figura 1) es una de las más simples, pues no necesita de imágenes con corrección atmosférica, y es similar a una "Diferencia simple entre bandas" cuyos términos de la adición son multiplicados por factores relacionados al eje formado por la recta de regresión de la radiometría de los pixeles de "no cambio" contenidos en las imágenes, identificados previamente en el terreno.

Este eje describe la correlación radiométrica entre los píxeles de no cambio en las imágenes de la primera y segunda fecha. En esta técnica el ángulo $(\theta)$ es obtenido como el arco tangente de la inclinación de la recta de regresión lineal de los puntos de no cambio como se muestra en la Figura 2. La selección de los puntos de "no cambio" para la regresión está basada en la interpretación de indicadores de campo, que permitan inferir sobre la no ocurrencia de cambios. Algunos de estos indicadores pueden ser la estructura madura de la cobertura vegetal, elementos arbóreos en estado de desarrollo adulto y formaciones nativas. La regresión lineal

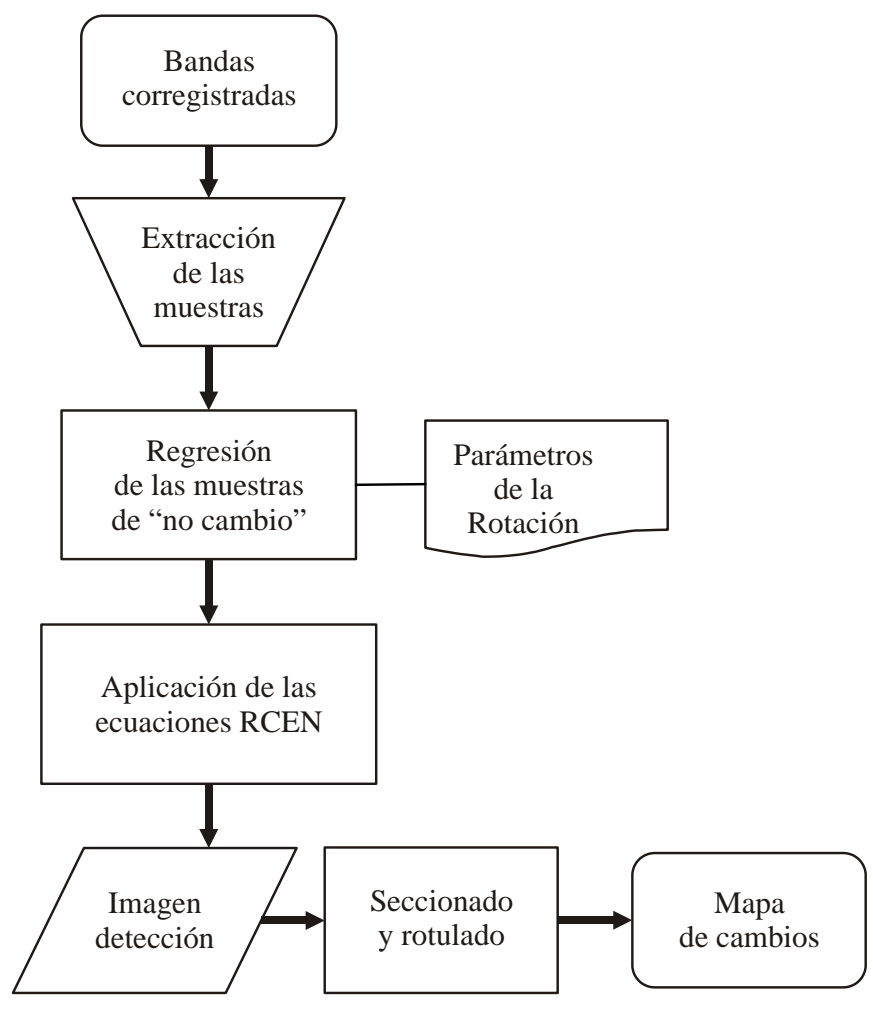

Figura 1. Diagrama de flujo de la técnica RCEN

de la radiometría de los puntos que no cambiaron puede ser obtenida posicionando en la imagen las muestras del trabajo de campo georreferenciadas que fueron rotuladas como "no cambio". A estos puntos de la imagen le corresponde un par de valores radiométricos con los que posteriormente será calculada la regresión. El primero de este par de valores corresponde a la fecha inicial del periodo de la detección y el segundo corresponde a la segunda fecha.

De esta forma el parámetro angular $(\theta)$ se calcula como el arco tangente del coeficiente de inclinación de la recta de regresión. Finalmente, la técnica de detección utiliza el ángulo $(\theta)$ para calcular los parámetros $(\mathrm{K})$ de la transformación (Ec. 1 y 2).

$$
\begin{aligned}
& \mathrm{K}_{2}=\cos (\theta) \\
& \mathrm{K}_{1}=\sin (\theta)
\end{aligned}
$$

La imagen de detección (o imagen intermedia) se calcula en la Ec. 3 y 4. En la Ec. 3 se muestra que la técnica se asemeja a una simple diferencia entre bandas, en la Ec. 4 fueron incluidos los coeficientes angulares obteniendo así la ecuación de la RCEN.

$$
\begin{gathered}
\mathrm{I}_{\text {intermedia }}=\mathrm{I}_{\text {Fecha 2 }}-\mathrm{I}_{\text {Fecha 1 }} \\
\mathrm{I}_{\text {intermedia }}=\mathrm{K}_{2} \times \mathrm{I}_{\text {Fecha 2 }}-\mathrm{K}_{1} \times \mathrm{I}_{\text {Fecha 1 }}
\end{gathered}
$$

Cuando se trata de detección de cambios en regiones con vegetación xerófila la Ec. 3 es aplicada solamente con bandas de rojo (Banda TM3), esta imagen intermedia de la Ec. 4 


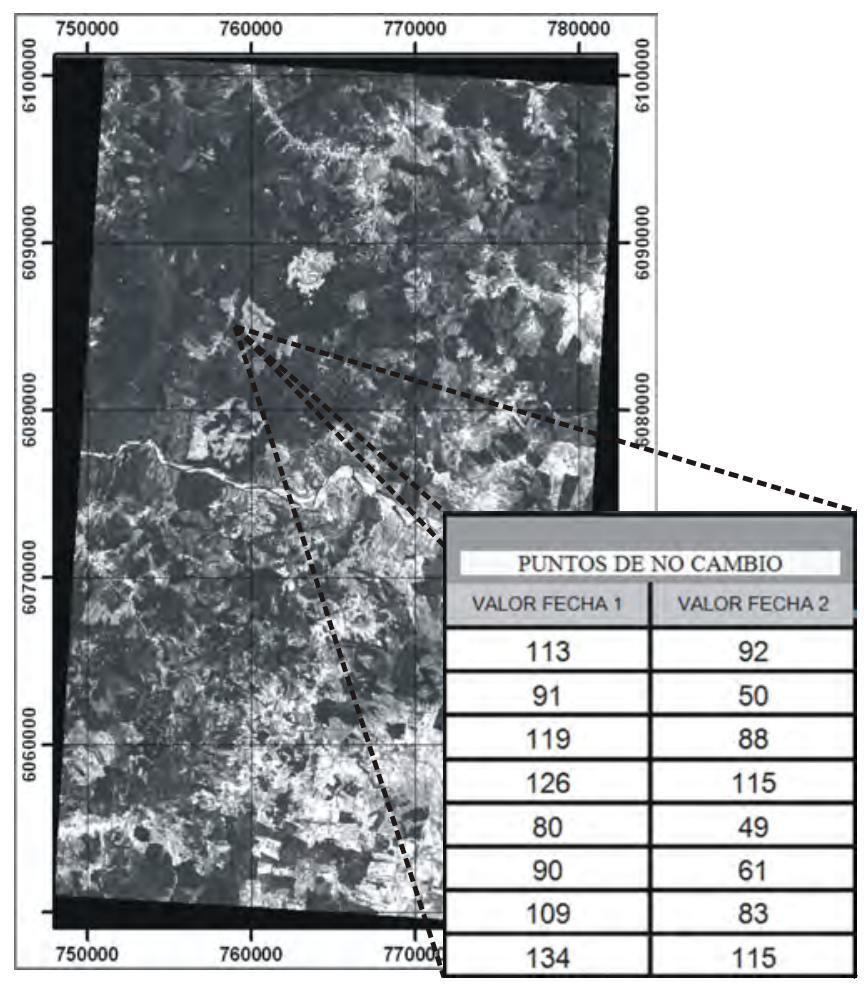

Imagen dos Bandas TM3 (Fechas 2004/2008)

Banda Fecha 1

Banda Fecha 2
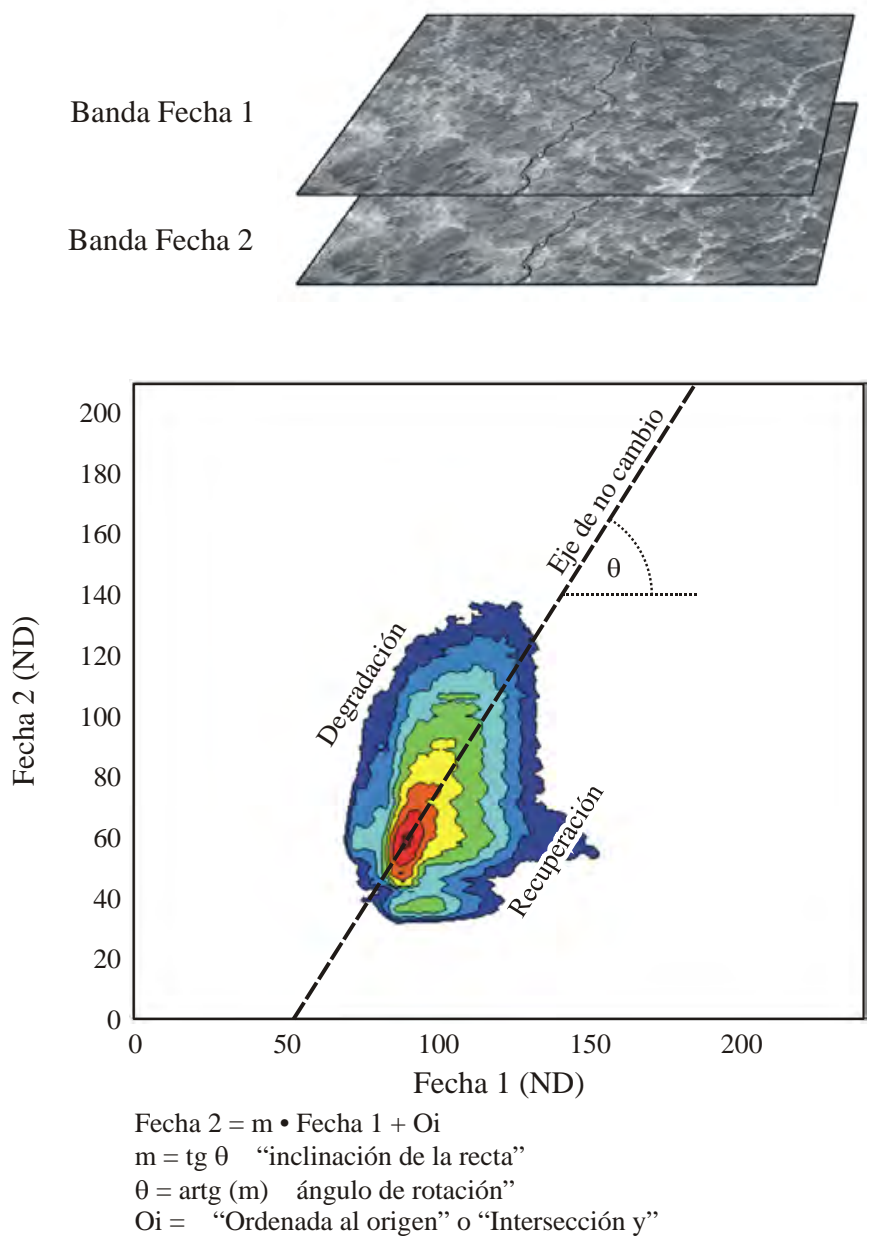

Figura 2. Diagrama analítico para obtener los parámetros de la técnica rotación en las images. 2004 al 2008 es la imagen detección. Sin embargo, cuando se trata de ambientes húmedos o subhúmedos y la vegetación predominante es mesófila la técnica necesita utilizar la banda del infrarrojo para eliminar la confusión en la detección, así, la ecuación final tiene la forma de la Ec. 5.

$$
\mathrm{I}_{\text {Detección }}=\mathrm{I}_{\text {intermedia Banda 3 }}-\mathrm{I}_{\text {intermedia Banda 4 }}
$$

En esta forma el algoritmo usado para obtener la imagen de detección (o intermedias) es aplicado para cada banda espectral, utilizando los parámetros angulares correspondientes que fueron determinados por la regresión de la radiometría para los puntos de "no cambio" de cada banda, finalmente las imágenes de detección intermedias son substraídas para producir con la Ec. 5 la imagen detección final.

Los cambios en la cobertura vegetal están relacionados inversamente con los cambios radiométricos en el rojo (TM3) y en forma directa con los cambios en el infrarrojo (TM4). De este modo cuando hay disminución de la cobertura vegetal, los valores de la radiometría en las bandas del rojo se incrementan, este aumento radiométrico, cuanto más intenso representa un cambio mayor ocurrido en el terreno. No ocurre lo mismo en el infrarrojo cercano, donde la disminución de cobertura vegetal produce una reducción del valor radiométrico, por esta razón en la suma de las imágenes intermedias, el término del infrarrojo es sumado con señal negativa.

En la etapa del seccionado, la imagen de detección formada por números continuos produce una imagen temática (números discretos), la que posteriormente es rotulada para obtener el "Mapa de cambios". El seccionado se efectúa con el cálculo de dos pares similares entre clases, dos para degradación y dos para recuperación. En la metodología adoptada, la imagen detección fue seccionada de modo empírico (Maldonado et al., 2007; Graça et al., 2008) con base en las observaciones de campo siguiendo las restricciones para el posicionamiento de los límites entre clases exigidos por la técnica RCEN. Los rótulos para las clases de cambio serán atribuidos de acuerdo a los intervalos de desviación estándar, basados en las estadísticas de las imágenes (Figura 3).

Las clases de degradación representan cambios en la cobertura de las tierras que están asociados con la pérdida de la cubierta vegetal la intensidad del cambio está reflejada por la intensidad de la radiometría. Por ejemplo, un cambio caracterizado por la sustitución de la cobertura forestal por suelo expuesto será asociado a una degradación fuerte (la intensidad radiométrica se encuentra a más de dos desviaciones estándar de la media de la imagen de detección). En el otro sentido, cambios caracterizados por el aumento de la cobertura vegetal tal como la conversión de un pastizal degradado a plantación, serán asociados a una recuperación fuerte (la radiometría tendrá valores menores que el límite localizado a una distancia de la media menos dos desviaciones estándar).

El mapeamiento generado por esta metodología es evaluado con el análisis del estadístico Kappa (Congalton, 1991; Congalton \& Green, 1999), basado en un muestreo de campo que representa las clases de dinámica del paisaje en términos 
A.

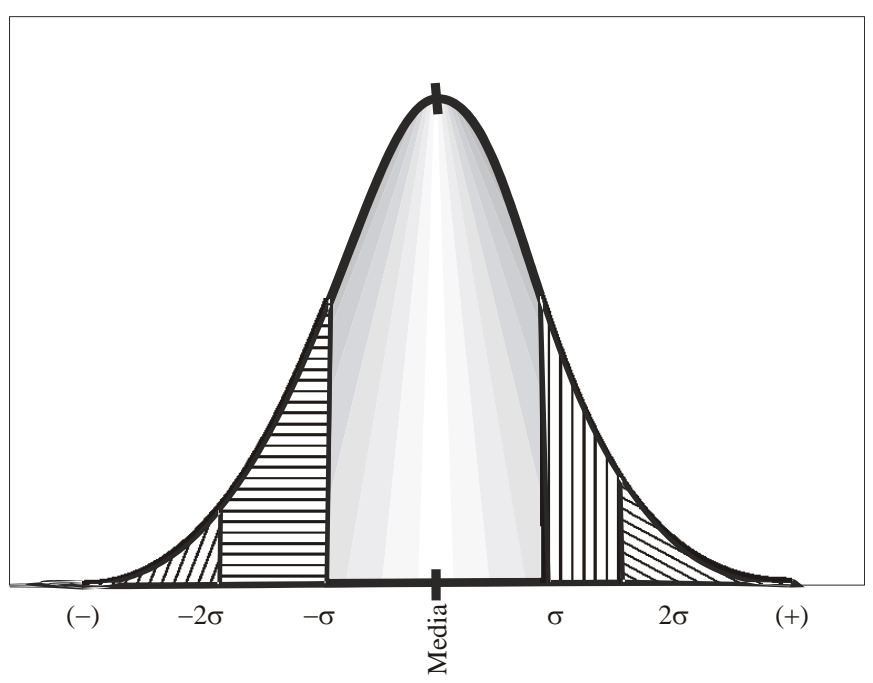

Histograma simétrico (Intervalo de tiempo largo)

B.

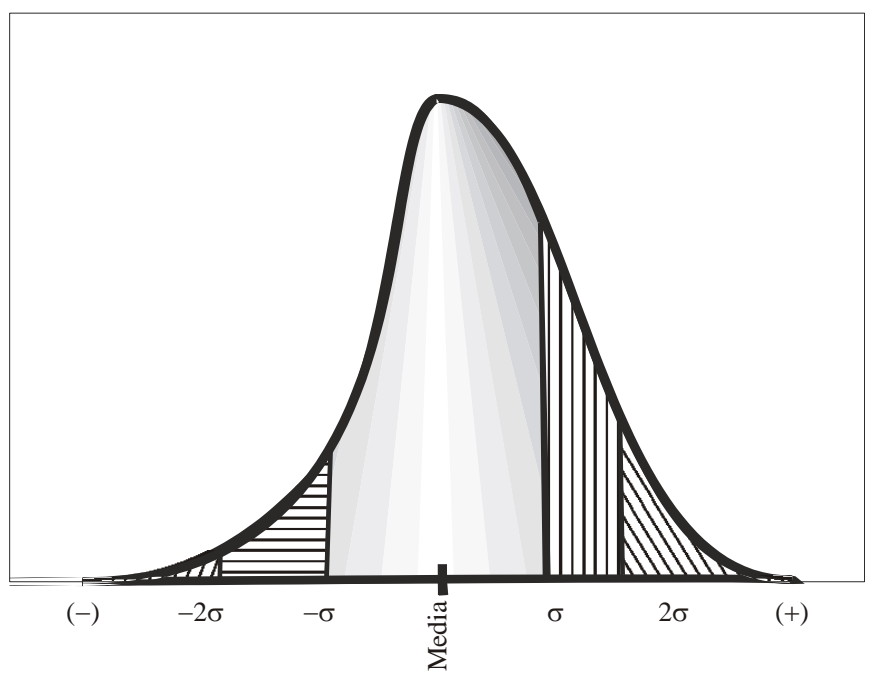

Histograma simétrico (Intervalo de tiempo corto)

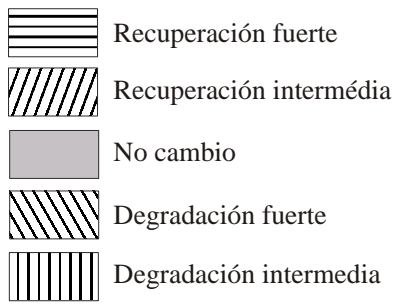

Figura 3. Histogramas de las imágenes de detección; cuando el espacio de tiempo considerado es suficiente para la recuperación (simétrico $(A)$ ) y cuando el tiempo considerado no es suficiente para lograr una recuperación en el paisaje (asimétrico (B))

de niveles de degradación y regeneración establecidos. El reconocimiento de campo es esencial para la aplicación de la técnica RCEN, la que está basada en puntos de control de "no cambio" (píxeles de cobertura de la tierra que no cambiaron en el intervalo de tiempo considerado), cuyas muestras colectadas deben ser debidamente georreferenciadas y fotografiadas para evaluar la exactitud del mapa. En este contexto, una campaña de campo fue organizada para muestrear un total de 150 puntos de control distribuidos uniformemente en la zona de estudio. De los puntos medidos en campo, 1/3 de ellos fueron colectados en sectores de "no cambio". La categoría, posición GPS, rumbo y registro fotográfico de cada punto fueron reunidos en la campaña de terreno.

\section{Relaciones de la dinámica forestal y la topografía}

La información topográfica ha sido derivada de los datos del "Shuttle Radar Topography Mission" (SRTM) con una resolución de $90 \mathrm{~m}$. El cálculo de la declividad fue precedido por el refinamiento del MDE original de datos SRTM, de 3' ( $90 \mathrm{~m})$ para 1' ( $30 \mathrm{~m})$ por krigagem (Valeriano et al., 2006), teniendo en cuenta las condiciones deseables para esta derivación (Valeriano, 2003a). Por lo tanto, los datos SRTM fueron tratados en dos etapas: la primera de ellas es el refinamiento de los datos y la segunda es la derivación del Modelo Digital de Elevación (MDE). Para el refinamiento, los datos fueron interpolados usando el método de "Kriging", con coeficientes seleccionados sobre una base experimental más amplia. Estudios precursores mostraron que las derivaciones de primer orden - declividad (Valeriano, 2003a) y de segundo orden - curvatura vertical (Valeriano, 2003b) son sensiblemente favorecidas por la condición mejorada de resolución y que la krigagem permite la manutención de las formas de segunda orden. El principio básico adoptado para el parámetro geomorfométrico de pendiente se fundamentó en el cálculo de la suma de los vectores ortogonales, calculados en función de los desniveles encontrados en una ventana móvil. Una vez que se ha obtenido los datos de pendientes de la zona, es posible realizar un cruzamiento entre la imagen de cambios y la imagen de declives para conseguir la distribución espacial o porcentual de los cambios (recuperación, degradación, no cambio, etc.) por fajas o rangos de pendientes.

\section{RESULTADOS Y DISCUSIÓN}

Los resultados del cálculo de pendiente permitieron caracterizar el relieve como abrupto y predominantemente montañoso. La zona de estudio presenta pendientes fuertes con un máximo de $154 \%$. En la Figura 4 se expone una representación de los valores continuos en niveles de gris invertidos. Se puede observar que el reducido número de zonas planas corresponden a planicies de los principales cursos de agua que drenan la región, entre los que destacan principalmente las zonas de los valles del río Maule y el Mataquito que son empleados para el uso de cultivos agrícolas.

La Figura 5 muestra la imagen de cambios resultante de la aplicación de la RCEN. El índice Kappa alcanzado fue de 0.74 , mostrando una adecuada concordancia entre el resultado de la técnica y los datos de validación colectados en la campaña de terreno. Se puede apreciar que un gran porcentaje $(78.5 \%)$ de la zona de estudio fue etiquetada en la categoría de "no cambio", indicando que las cubiertas entre los años 2004 y 2008 no registraron ganancias o pérdidas significativas en su expresión vegetativa, seguido de un 16.9 y un $4.6 \%$ para las categorías de recuperación y degradación de la vegetación respectivamente. 


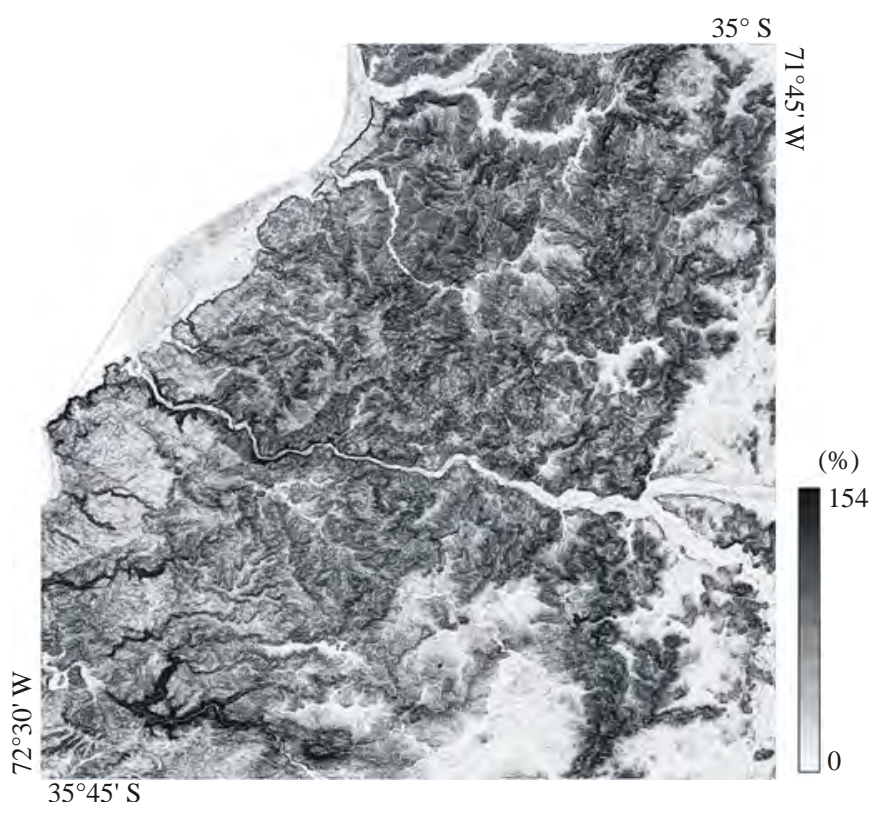

Figura 4. Distribución de los valores de pendientes para el área de estudio (en recuadro)

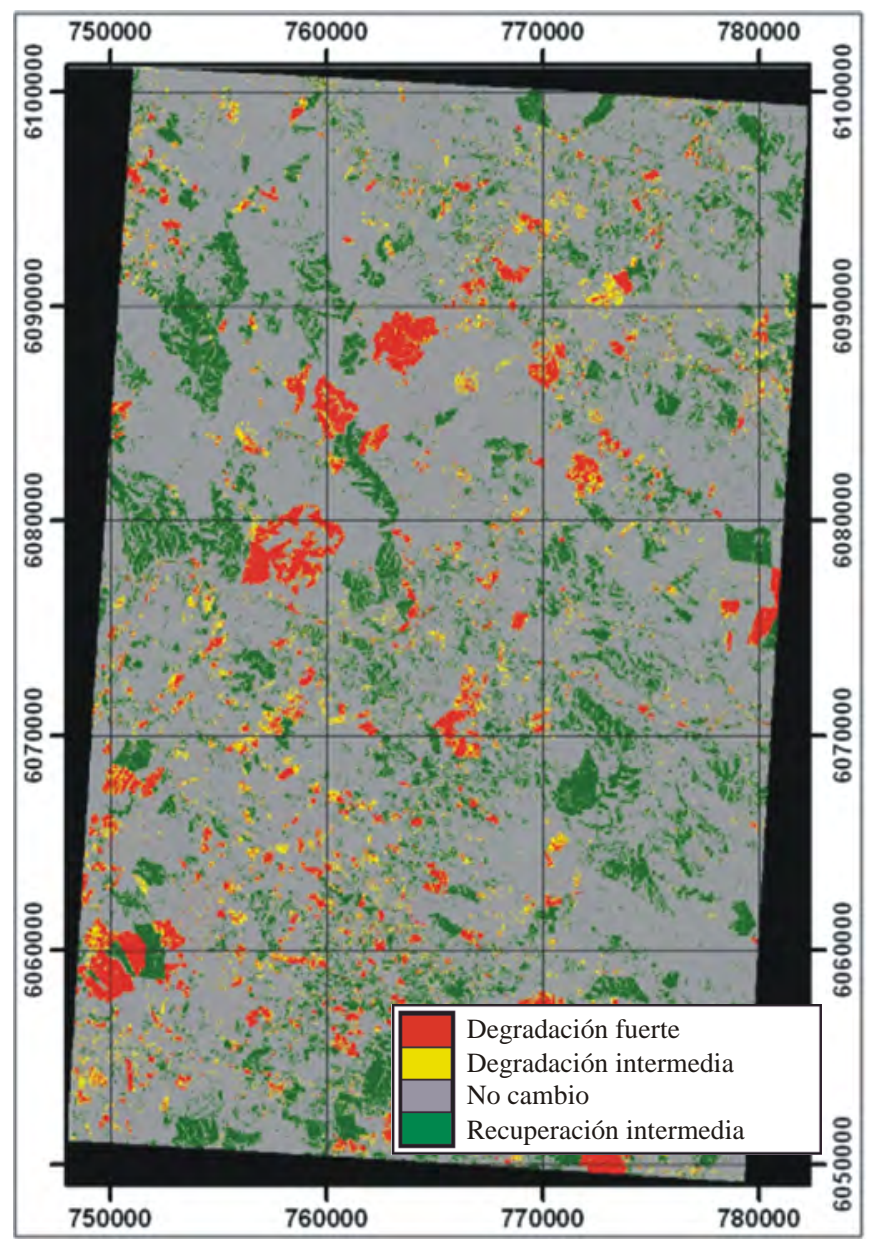

Figura 5. Imagen de los cambios ocurridos entre M arzo de 2004 y Enero de 2008
La obtención de la imagen detección utilizando información de rojo e infrarrojo permitió discriminar bien los cambios en ambiente natural, cultivos y forestaciones jóvenes (Figura 5). Después de una cierta edad de la forestación, la parcela aparece como no cambio en la imagen detección aunque continúe el crecimiento. Esta situación de la vegetación se debe a la saturación del rojo e infrarrojo (Banda TM3 y TM4) después de cierta densidad foliar de la plantación, sobre todo después de 12 o 13 años.

La Figura 6 evidencia similares niveles de precipitación en la Estación meteorológica de Forel ( $35^{\circ} 24^{\prime} 44^{\prime}$,, $\left.72^{\circ} 11^{\prime} 54^{\prime \prime}\right)$ para los meses anteriores a las fechas de las imágenes estudiadas. Se observan precipitaciones mensuales menores a $5 \mathrm{~mm}$, lo cual permite estimar que las lluvias no fueron influyentes sobre la detección de los cambios generados en el paisaje. De hecho, se aprecia que los valores acumulados alcanzados (506 mm a Febrero 2004 y $516 \mathrm{~mm}$ a Enero 2008), se encuentran bajo la media $(734 \mathrm{~mm})$ reportada, lo que muestra un déficit pluviométrico en la zona (DGA, 2009).

La Tabla 1 evidencia la distribución de los cambios ge-
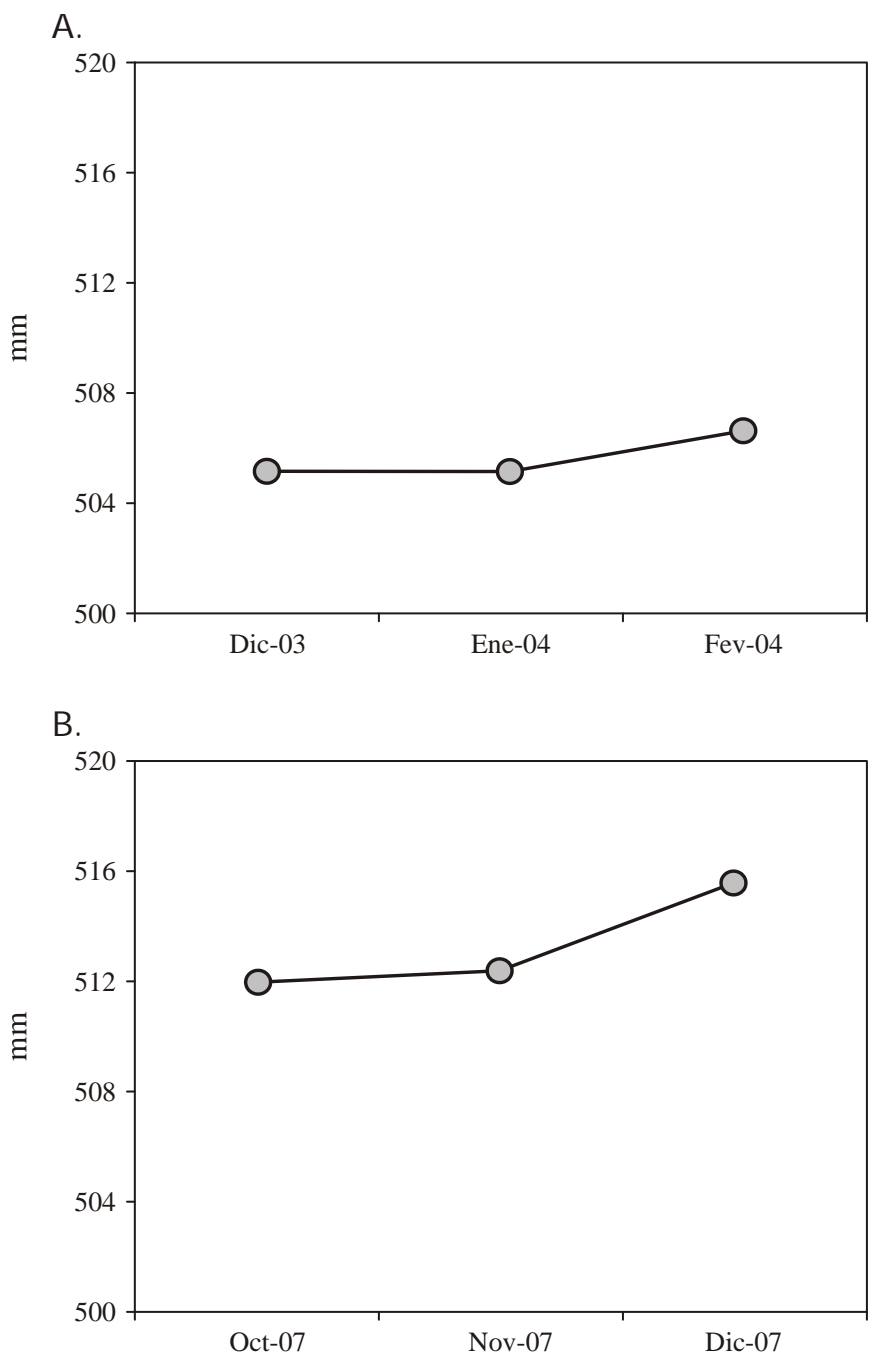

Figura 6. Precipitaciones acumuladas $(\mathrm{mm})$ de los tres meses anteriores a la obtención de las imagenes, en (A) fecha 1, y en (B) fecha 2 (Estación meteorológica de Forel) 
nerados por rangos de pendientes. Es posible apreciar que en aquellos rangos de pendientes inferiores al $10 \%$, la proporción de zonas de estabilidad o "no cambio" alcanzó un $80 \%$, lo cual se puede asociar principalmente al reducido lapso de tiempo transcurrido ( 4 años) entre la fecha 1 y fecha 2 de las imágenes analizadas, periodo en el cual no se generaron grandes intervenciones en el territorio, por lo que no se detectan mayores cambios en el paisaje. En las zonas de estabilidad se encuentran sectores que incluyen praderas de pastoreo, barbechos de cultivos anuales de subsistencia (trigo, lentejas, garbanzos, entre otros) y cultivos agrícolas de secano (antiguos viñedos de producción artesanal).

\section{Tabla 1. Distribución de los cambios por rangos de pendiente}

\begin{tabular}{lccc}
\hline \multicolumn{1}{c}{ Pendiente } & Recuperación & Degradación & No cambio \\
Menor $10 \%$ & 0,112 & 0,081 & 0,806 \\
10 a $20 \%$ & 0,163 & 0,083 & 0,754 \\
20 a $30 \%$ & 0,173 & 0,083 & 0,744 \\
30 a $40 \%$ & 0,161 & 0,085 & 0,753 \\
40 a $50 \%$ & 0,151 & 0,089 & 0,760 \\
Mayor de $50 \%$ & 0,125 & 0,077 & 0,799 \\
\hline
\end{tabular}

En el mismo rango de pendientes, el bajo valor (11\%) alcanzado por las zonas de "recuperación", incluyen la integración de nuevos cultivos agrícolas intensivos que requieren una mayor inversión en tecnologías de producción (por ejemplo, viñas y olivos) y que se han visto beneficiados por las ventajas comparativas naturales de la zona, la modernización agrícola de Chile y la formación de clusters productivos, cuyos cultivos se sitúan ahora en zonas donde antiguamente existían praderas y matorrales esclerófilos de poca altura (Romero et al., 2004).

Por otra parte, las zonas con un mayor rango de pendientes (sobre $50 \%$ ), evidenciaron también una alta proporción (79\%) de superficie etiquetada como "no cambio", sin embargo, a diferencia del rango mencionado anteriormente, esta estabilidad del paisaje se debe a zonas que poseen plantaciones forestales con edades por sobre los 12 años aproximadamente y a sectores con bosque nativo adulto, en donde la saturación de la banda del infrarrojo (TM4) es incapaz de cuantificar el aumento de la densidad foliar después de cierto nivel.

En cuanto a la categoría de "recuperación" para este rango de pendientes, el efecto se debe casi exclusivamente a la capacidad de la técnica de medir aquellas zonas que registran crecimiento de plantaciones forestales jóvenes, reforestación comercial, o el establecimiento de nuevos bosques artificiales en zonas que se encontraban cosechadas o taladas, situación que describe un proceso de rotación productiva típico de las empresas forestales que se dedican a la obtención de madera y pulpa de celulosa (Donoso \& Otero, 2005).

Con respecto a las zonas donde se presentó "degradación" de la cubierta vegetal, la Tabla 1 indica que esta categoría no se ve influenciada por los rangos de pendientes, ya que se presenta con proporciones (8\%) similares a través de todo el gradiente de la variable geomorfométrica, aún así, la pérdida de vegetación puede deberse a la sustitución en menor medida, de zonas con bosque nativo y matorrales por otras cubiertas agrícolas y praderas de pastoreo en los sectores más planos (bajo los 200 metros de elevación), y actividades de cosechas forestales de plantaciones artificiales adultas en zonas de mayor pendiente (Echeverría et al., 2006).

En cuanto a rangos de pendiente existente entre los 10 y $50 \%$, se puede observar una proporción de "recuperación" promedio de $16 \%$, un poco más alto que los extremos anteriormente comentados, posible de asociar al establecimiento de nuevas plantaciones, cultivos agrícolas o crecimiento de bosques artificiales jóvenes. Para el mismo rango, las zonas catalogadas como "no cambio" (proporción promedio de $75 \%$ ) se deben principalmente a la mantención temporal de cultivos agrícolas de secano en las zonas de pendientes bajas, junto con bosque nativo y plantaciones artificiales adultas en las zonas de pendientes intermedias $\mathrm{y}$ altas.

Finalmente, en términos generales los resultados indican que las transformaciones a largo plazo que se están realizando en el secano costero de la Región del Maule durante el último tiempo, se encuentran asociadas a la modernización de la agricultura y el aumento de la actividad forestal. Lamentablemente, esto no ha provocado un aumento en el desarrollo y mejora de la calidad de vida de las personas que habitan en dichas zonas, sino que han generado migraciones, disminuciones en los índices de desarrollo humano, fragmentación del bosque nativo y reducción de la biodiversidad, según lo reportado por autores como Romero et al. (2004) y Donoso \& Otero (2005).

Por esta razón, se hace necesario contar con información confiable que permita dar cuenta de los cambios que se están produciendo en el paisaje forestal, para evitar situaciones de sustitución y degradación que con el tiempo se vuelven prácticamente irreversibles (Echeverría et al., 2006). La identificación, caracterización y cuantificación de estos fenómenos son importantes para facilitar futuros manejos del paisaje y monitorear acciones, centradas en la biodiversidad, conservación y uso sustentable del recurso.

\section{CONCLUSIONES}

1. La técnica permitió obtener un mapa de los cambios del territorio sin invertir demasiado tiempo de procesamiento computacional en los datos.

2. La técnica del RCEN ha permitido la confección de una imagen panorámica acerca del fenómeno de la degradación del paisaje, el cual en zonas planas ha aumentado la sustitución de praderas y matorrales nativos por cultivos agrícolas de mayor retorno económico (olivares y viñedos) gracias a la inclusión de avances en la agricultura como el riego tecnificado.

3. El fenómeno de la degradación del paisaje (sustitución de especies, cosechas mecanizadas y monocultivos forestales) se expresa en las zonas de mayor pendiente como el resultado de políticas de forestación y las actividades de empresas forestales ligadas al rubro de la producción de celulosa y madera. 


\section{LITERATURA CITADA}

Accioly, L. J. O.; Pacheco, A.; Costa, T. C. C.; Lopes, O. F.; Oliveira, M. A. J. Relações empíricas entre a estrutura da vegetação e dados do sensor TM/LANDSAT. Revista Brasileira de Engenharia Agrícola e Ambiental, v.6, n.3, p.492-498, 2002.

Berberoglu, S.; Akin, A. Assessing different remote sensing tecniques to detect land use/cover changes in the eastern Mediterranean. International Journal of Applied Earth Observation and Geoinformation, v.11, p.46-53, 2009.

Chagas, C. S.; Vieira, C. A. O.; Fernandes Filho, E. I.; Carvalho Junior, W. Utilização de redes neurais artificiais na classificação de níveis de degradação em pastagens. Revista Brasileira de Engenharia Agrícola e Ambiental, v.13, n.3, p.319-327, 2009.

CIREN - Centro de Información de Recursos Naturales. Estudio agrologico VII región. Descripción de Suelos. Materiales y símbolos. Santiago: Publicaciones CIREN, 1997, n.117. 624p.

CONAF - Corporación Nacional Forestal. Diagnóstico de la desertificación en Chile. Ministerio de Agricultura. Santiago: Publicaciones CONAF, 1997. 399p.

Congalton, R. G. Calculus of kappa. Remote Sensing of Environment, v.37, n.1, p.35-41, 1991.

Congalton, R. G.; Green, K. Assessing the accuracy of remotely sensed data: principles and practice. Mapping sciences series. New York: CRC Press Inc., 1999. 98p.

Coppin, P.; Jonckheere, I.; Nackaerts, K.; Muys, B.; Lambin, E. Digital change detection methods in ecosystem monitoring: A review. International Journal of Remote Sensing, v.5, n.25, p.1565-1596, 2004.

Desclee, B.; Bogaert, P.; Defourny, P. Forest change detection by statistical object-based method. Remote Sensing of Environment, v.102, n.1, p.1-11, 2006.

DGA - Dirección General de Aguas. Ministerio de obras hidráulicas. Chile. Departamento de Hidrología. Datos hidrológicos actuales. 2009. http://dgasatel.moptt.cl/. 20 Dez.2009.

Donoso, P.; Otero, L. Hacia una definición de país forestal: Dónde se sitúa Chile? Revista Bosque, v.26, n.3, p.5-18, 2005.

Echeverrría, C.; Cayuela, L.; Manson, R.; Coomes, D.; Lara, A.; Rey-Benayas, J.; Newton, A. Spatial and temporal patterns of forest loss and fragmentation in Mexico and Chile. In: Newton, A. Biodiversity loss and conservation in fragmented forest landscapes: the forest of montane Mexico and temperate South America. Londres: Bournmouth University, 2007. 432p.

Echeverría, C.; Coomes, D.; Salas, J.; Rey-Benayas, J.; Lara, A.; Newton, A. Rapid deforestation and fragmentation of Chilean temperate forests. Biological Conservation, v.130, n.4, p.481-494, 2006.

Gajardo, R. La vegetación natural de Chile. Clasificación y distribución geográfica. Santiago: Editorial Universitária, 1994. $165 \mathrm{p}$.

Graça, P. M. L. A.; Maldonado, F. D.; Santos, J. R.; Soares, J. V. Detecção de corte seletivo de madeira por técnica de rotação radiométrica na floresta Amazônica. Revista Ambiência, v.4, p.97-106, 2008.

Hall, O.; Hay, J. H. A multiscale object-specific approach to digital change detection. International Journal of Applied Observation and Geoinformation, v.4, p.311-327, 2003.
Lara, A.; Cortés, M.; Echeverría, C. Bosques. In: Sunkel, O. Informe país: Estado actual del medio ambiente en Chile. Centro de estudios de políticas públicas. Santiago: Universidad de Chile, 2000. p.131-173.

Le Hégarat-Mascle, S.; Seltz, R. Automatic change detection by evidential fusion of change indices. Remote Sensing of Environment, v.91, n.3-4, p.390-404, 2004.

Lillestrand, R. L. Techniques for change detection. IEEE Transactions on Computers, v.21, n.1, p.655-659, 1972.

Lima, J. R.; Barbosa, M. P.; Dantas Neto, J. Avaliação do incremento de açudes e sua relação com o uso do solo, através do uso de imagens TM/Landsat-5: Estudo de caso. Revista Brasileira de Engenharia Agrícola e Ambiental, v.2, n.2, p.243-245, 1998.

Liua, D.; Song, K.; Townshend, J. R. G.; Gong, P. Using local transition probability models in Markov random fields for forest change detection. Remote Sensing of Environment, v.112, n.5, p.2222-2231, 2008.

Maldonado, F. D.; Santos, J. R.; Graça, P. M. L. Change detection technique based on the radiometric rotation controlled by nochange axis, applied on a semi-arid landscape. International Journal of Remote Sensing, v.28, n.8, p.1001-1016, 2007.

Nackaerts, K.; Vaesen, K.; Muys, B.; Coppin, P. Comparative performance of a modified change vector analysis in forest change detection. International Journal of Remote Sensing, v.26, p.839-852, 2005.

Nascimento, M. C.; Riva, R. D. D.; Chagas, C. S.; Oliveira, H.; Dias, L. E.; Fernandes Filho, E. I.; Soares, V. P. Uso de imagens do sensor ASTER na identificação de níveis de degradação em pastagens. Revista Brasileira de Engenharia Agrícola e Ambiental, v.10, n.1, p.196-202, 2006.

Nelson, T.; Wilson, H. G.; Boots, B.; Wulder, M. A. Use of ordinal conversion for radiometric normalization and change detection. International Journal of Remote Sensing, v.26, p.535-541, 2005.

Radke, R. J.; Andra, S.; Al-Kofahi, O.; Roysam, B. Image change detection algorithms: A systematic survey. IEEE Transactions on Image Processing, v.14, n.3, p.294-307, 2005.

Rogan, J.; Franklin, J.; Roberts, D. A. A comparison of methods for monitoring multitemporal vegetation change using Thematic Mapper imagery. Remote Sensing of Environment, v.80, p.143-156, 2002.

Romero, H.; Vásquez, A.; Muñoz, L. La vitivinicultura moderna en Chile: Caracterización de su evolución reciente y dificultades para el desarrollo local. In: Congreso Territorio y Desarro1lo, 25, e Internacional de Geografía, 10, Valdivia, Anales... Valdivia: Universidad Austral de Chile, 2004. 426p.

San Martín, J.; Donoso, C. Estructura florística e impacto antrópico en el bosque maulino de Chile. In: Armesto, J; Villagrán; Arroyo, M. Ecología de los bosques nativos de Chile. Santiago: Editorial Universitaria, 1997. p.153-168.

Santibáñez, F.; Parada, M.; Ulriksen, P. Perspectivas de desarrollo de los recursos de la VII Región. Distritos Agroclimáticos. IREN/CORFO Instituto de investigaciones de recursos naturales. Santiago: IREN, 1979. 155p. Publicaciones n.25.

Singh, A. Digital change detection techniques using remotely-sensed data. International Journal of Remote Sensing, v.10, n.6, p.989-1003, 1989. 
Song, C.; Woodcock, C. E.; Seto, K. C.; Lenney, M.P.; Macomber, S. A. Classification and change detection using Landsat TM data: When and how to correct atmospheric effects? Remote Sensing of Environment, v.75, n.1, p.230-244, 2001.

Valeriano, M. M. Mapeamento da declividade em microbacias com sistemas de informação geográfica. Revista Brasileira de Engenharia Agrícola e Ambiental, v.7, n.2, p.303-310, 2003 a.
Valeriano, M. M. Curvatura vertical de vertentes em microbacias pela análise de modelos digitais de elevação. Revista Brasileira de Engenharia Agrícola e Ambiental, v.7, n.3, p.539-546, 2003b.

Valeriano, M. M.; Kuplich, T. M.; Storino, M.; Amaral, B.; Mendes Jr., J.; Lima, D.; Modeling small watersheds in Brazilian Amazonia with shuttle radar topographic mission-90m data. Computers \& Geosciences, v.32, n.8, p.1169-1181, 2006. 